Proportion of South Asian participants in six multicentre clinical trials

\begin{tabular}{|c|c|c|c|c|c|}
\hline \multirow[b]{2}{*}{ Trial type } & \multicolumn{3}{|c|}{ Trial population } & \multirow[b]{2}{*}{ Recruitment figures } & \multirow{2}{*}{$\begin{array}{c}\text { No (\%) South Asian } \\
\text { participants }\end{array}$} \\
\hline & Sex & Age (years) & Recruitment & & \\
\hline Hysterectomy & Female & $>18$ (mean 41.2 (SD 8)) & National & 1380 randomised & $8(0.6 \%)$ \\
\hline \multicolumn{6}{|l|}{ Cancer: } \\
\hline Colorectal & Male and female & $>18$ (mean 69; range 25-94) & National & $\begin{array}{c}584 \text { on whom ethnicity } \\
\text { data are available }\end{array}$ & $1(0.2 \%)$ \\
\hline Breast & $\begin{array}{c}\text { Female } \\
\text { (post-menopausal) }\end{array}$ & Mean 64 & Regional & 780 randomised & $2(0.3 \%)$ \\
\hline Breast & $\begin{array}{c}\text { Female } \\
\text { (post-menopausal) }\end{array}$ & Most $>55$ & Regional & 133 randomised & $0(0 \%)$ \\
\hline \multirow[t]{2}{*}{ Ovarian } & Female & $>18^{*}$ & Regional & $\begin{array}{c}480 \text { registered } \\
(242 \text { randomised) }\end{array}$ & $3(0.6 \%)$ \\
\hline & & & National & $\begin{array}{c}559 \text { registered } \\
(300 \text { randomised) }\end{array}$ & $4(0.7 \%)$ \\
\hline $\begin{array}{l}\text { Helicobacter pylori } \\
\text { eradication }\end{array}$ & Male and female & $40-49$ & Regional & 8407 participants & $145(1.7 \%)$ \\
\hline
\end{tabular}

Office for National Statistics' latest estimates of proportion of population that is of South Asian origin are 3.8\% for the Yorkshire-Humber region and 3.4\% for Great Britain as a whole. ${ }^{3}$

${ }^{*}$ Range and mean unknown.

Asian population. We would have liked to compare more precisely the trials' inclusion criteria of age range and sex with those of the expected South Asian population, but this information is not currently available. Trials that recruited older patients would not be expected to comprise a percentage of South Asian people equal to the overall figures of the Office for National Statistics because the number of elderly South Asian people in the UK population is small.

Increased awareness and monitoring of recruitment and retention of ethnic minority groups in clinical trials are needed, and analysis of data by ethnicity of subjects should be done consistently. More rigorous review by the research ethics committee of clinical trial protocols, payment for translation of information supplied to participants, community participation, and education of ethnic minority groups may contribute to attaining proportional representation of ethnic minorities in trials.
Contributors: SM had the idea to write the report, collated the data, helped to draft the report, and critically revised it. MH-G, $\mathrm{JB}, \mathrm{BL}$, and $\mathrm{KA}$ helped to formulate and revise the report. MH-G also helped to draft the report. All authors have seen and approved the final version. SM is the guarantor.

Funding: NHS Health Technology Assessment Programme. The views in the paper are those of the authors and not necessarily those of the Department of Health.

Competing interests: None declared.

1 Ashcroft R, Chadwick DW, Clark SRL, Edwards RHT, Frith L, Hutton JL. Implications of socio-cultural contexts for the ethics of clinical trials Health Technol Assess 1997;1:1-65.

2 Britton A, McKee M, Black N, McPherson K, Sanderson C, Bain C. Threats to applicability of randomised trials: exclusion and selective participation. J Health Serv Res Policy 1999;4:112-21.

3 Scott A, Pearce D, Goldblatt P. The sizes and characteristics of the minority ethnic populations of Great Britain-latest estimates. Popul Trends 2001;105:6-10.

4 Kressin NR, Meterko M, Wilson NJ. Racial disparities in participation in biomedical research. J Natl Med Assoc 2000;92:62-9.

5 Matthews HW. Racial, ethnic and gender differences in response to mediMatthews HW. Racial, ethnic and gender differences in res
cines [review]. Drug Metabol Drug Interact 1995;12:77-91. (Accepted 5 February 2003)

\title{
Average energy intake among pregnant women carrying a boy compared with a girl
}

\author{
Rulla M Tamimi, Pagona Lagiou, Lorelei A Mucci, Chung-Cheng Hsieh, Hans-Olov Adami, \\ Dimitrios Trichopoulos
}

The birth weight of boys is about $100 \mathrm{~g}$ heavier than the birth weight of girls, and this seems to be consistent across populations. No study, has examined whether the difference is because the pregnant woman has a higher energy intake or more efficient energy utilisation if she is carrying a male embryo than if she is carrying a female embryo. We report data to support the first hypothesis-that the pregnant woman carrying a boy has a higher energy intake.

\section{Participants, methods, and results}

We analysed data from an international prospective study on dietary and non-dietary predictors of pregnancy hormones and outcomes among women in Boston, United States, and Shanghai, China. ${ }^{1}$ Because the database of nutrients for the Chinese diet is incomplete, we present data on dietary intakes for the US women only.

Between March 1994 and October 1995, we identified 402 eligible pregnant women during their first routine prenatal visit at the Beth Israel Hospital in Boston and invited them to participate in the study. We followed throughout their pregnancies the 304 women who consented and did not have an early pregnancy termination or twin birth. The study population, study design, and methods have been described.
Pregnant women carrying boys have a $10 \%$ higher energy intake than those carrying girls

continued over 
Department of Epidemiology, Harvard School of Public Health, Boston, MA 02115,

USA

Rulla M Tamimi doctoral student Dimitrios

Trichopoulos professor

Department of Hygiene and Epidemiology, School of Medicine, University of Athens, GR-11527, Athens, Greece Pagona Lagiou assistant professor

University of Massachusetts Cancer Center, Worcester, MA01655, USA Chung-Cheng Hsieh professor

Department of Medical

Epidemiology, Karolinska Institutet,

Stockholm, SE-171 77 , Sweden Lorelei A Mucci postdoctoral fellow Hans-Olov Adami professor

Correspondence to: D Trichopoulos dtrichop@hsph. harvard.edu

Multiple regression derived mutually adjusted ${ }^{*}$ differences in the daily energy intake of 244 women in Boston, 1994-5, during the second trimester of pregnancy

\begin{tabular}{|c|c|c|}
\hline & Mean $(95 \% \mathrm{Cl})$ change in energy intake $(\mathrm{kJ} /$ day) & $P$ value \\
\hline \multicolumn{3}{|l|}{ Sex of fetus: } \\
\hline Female & 1.0 & \\
\hline Male & $796.2(8.9$ to 1583.4$)$ & 0.05 \\
\hline \multicolumn{3}{|l|}{ Maternal age (years): } \\
\hline$<30$ & 1.0 & \\
\hline $30-34$ & $157.2(-743.6$ to 1057.9$)$ & 0.73 \\
\hline $35-38$ & 1104.2 (-489.0 to 2697.3$)$ & 0.18 \\
\hline Maternal education per level of education $†$ increase & 417.4 (-158.6 to 993.3$)$ & 0.16 \\
\hline
\end{tabular}

Parity:

\begin{tabular}{lcc}
\hline 1 & 1.0 & \\
\hline 2 & $-138.8(-987.2$ to 709.5$)$ & 0.75 \\
\hline Maternal height per $5 \mathrm{~cm}$ increase & $323.8(-10.7$ to 658.2$)$ & 0.06 \\
\hline Pre-pregnancy weight per $5 \mathrm{~kg}$ increase & $122.0(-133.0$ to 376.5$)$ & 0.35 \\
\hline Maternal weight gain per kg increase & $156.4(68.7$ to 244.1$)$ & $<0.001$ \\
\hline Gestational age at birth per week increase & $-34.5(-240.4$ to 171.4$)$ & 0.74
\end{tabular}

${ }^{*}$ Adjusted for maternal age (categorically), maternal education (ordinally), parity (categorically), maternal height (continuously), weight before pregnancy (continuously), maternal weight gain up to gestational week 27 (continuously), and exact gestational age at delivery (continuously), estimated from the difference between the date of last menstruation and date of delivery.

†Level 1=high school education; level $2=$ college education; level $3=$ graduate education.

We assessed dietary intake during the second trimester by using an extensive questionnaire on the frequency of eating, which is identical to the one used and validated in the nurses' health study. ${ }^{2}$ Trained interviewers checked the questionnaire for accuracy and completeness before we mailed it to the women one week before their second prenatal visit (around 27 weeks' gestation). We calculated intake of energy and energy generating nutrients from the data on dietary intake, using standard software. ${ }^{3}$ The analysis included 244 pregnant women with adequate covariate and dietary data.

We followed simple cross tabulations and modelled the data through multiple linear regression. The sex of the embryo was our main interest and dependent variables, one at a time, were intakes of energy, animal lipids, vegetable lipids, carbohydrates, and proteins.

Women who were carrying a male embryo had a higher daily energy intake than women who were carrying a female embryo (mean 9025.6 (SE=369.6) kJ $v 8258.6(227.2) \mathrm{kJ}$ ). After adjustment for potentially confounding covariates indicated in the table, the difference was $796.2 \mathrm{~kJ}(\mathrm{P}=0.049)$, or 9.6\%. We did not observe any effect of sex of the fetus on maternal weight gain, even though weight gain is positively associated with birth weight. Pre-eclampsia, emesis gravidarum, tobacco smoking, and alcohol drinking during pregnancy were not confounders of this relation.

Women carrying male rather than female fetuses had an $8.0 \%$ higher intake of protein, a $9.2 \%$ higher intake of carbohydrates, a 10.9\% higher intake of lipids of animal origin, and a 14.9\% higher intake of lipids of vegetable origin. There is no significant heterogeneity among these higher intakes, even though higher intakes tend to be concentrated in the energy dense lipids.

\section{Comment}

The energy intake of pregnant women is about $10 \%$ higher when they are carrying a boy rather than a girl.
Our findings support the hypothesis that women carrying male rather than female embryos may have higher energy requirements and that male embryos may be more susceptible to energy restriction. ${ }^{4}$ Although marginally significant, the difference in energy intake between pregnant women carrying boys rather than girls is not trivial-modelling the data through logistic regression indicates that the odds of having a boy rather than a girl is higher by about 35\% when maternal energy intake is higher by about one standard deviation. The signal from the fetus responsible for the higher energy intake of women carrying a boy could be related to the strongly anabolic testosterone secreted by the fetal testicles, ${ }^{5}$ but other alternatives deserve scientific investigation.

Contributors: RT, PL, and LM performed the study. The original international study was conceived by $\mathrm{CcH}, \mathrm{H}-\mathrm{OA}$, and DT, who also provided input in the statistical analysis. All authors contributed to the interpretation of the results and the preparation of the manuscript. DT is the guarantor for the data.

Funding: This study was supported in part by grant no CA54220 from the National Institutes of Health. The funding source approved the original study but had no further involvement in the present investigation.

Competing interests: None declared.

Ethical approval: The study was in accordance with the ethical standards for human experimentation established by the Institutional Review Boards of the Harvard School of Public Health and Beth Israel Hospital.

1 Lipworth L, Hsieh CC, Wide L, Ekbom A, Yu SZ, Yu GP, et al. Materna pregnancy hormone levels in an area with a high incidence (Boston, USA) and in an area with a low incidence (Shanghai, China) of breas cancer. Br J Cancer 1999;79:7-12.

2 Willett WC, Sampson L, Stampfer MJ, Rosner B, Bain C, Witschi J, et al. Reproducibility and validity of a semiquantitative food frequency questionnaire. Am J Epidemiol 1985;122:51-65.

3 Romieu I, Stampfer MJ, Stryker WS, Hernandez M, Kaplan L, Sober A, et al. Food predictors of plasma beta-carotene and alpha-tocopherol: validation of a food frequency questionnaire. Am J Epidemio 1990;131:864-76.

4 Susser M. Maternal weight gain, infant birth weight, and diet: causal sequences. Am J Clin Nutr 1991;53:1384-96.

5 Yen SSC, Jaffe RB, Barbieri RL, eds. Reproductive endocrinology: physiology, pathophysiology and clinical management. 4th ed. Philadelphia, PA: Saunders, 1999 . 